\title{
Britain caught out by 'unscientific' reactions to Europe's beef crisis
}

Paris. Politics triumphed over science again last week in the bovine spongiform encephalopathy (BSE) crisis, when the European Union (EU) flew in the face of its own scientific advice and rejected a partial lifting of an embargo of British beef products. The decision has strengthened calls for a more rational handling of the crisis based on a clear scientific assessment of the risks involved.

But this seems unlikely to happen soon. Much of the European public - and most of the governments - remain deeply sceptical of scientific advice on the matter, perceiving that it has been to slow to acknowledge the possibility that the agent that causes bovine spongiform encephalopathy (BSE) could pass to humans and cause Creutzfeldt-Jakob disease (CJD).

The decision by the EU's Standing Veterinary Committee to reject the lifting of the ban on British gelatine, tallow and bull semen was largely a reflection of the political stance taken by different countries. The committee overruled advice from its own Scientific Veterinary Committee, which said that semen was safe, and that so too were gelatine and tallow, provided that strict controls were used in their production.

The same position was also adopted earlier this month by both the World Health Organization (WHO) and the World Organization for Animal Health (Office International des Epizooties, or OIE), a body that establishes guidelines designed to facilitate trade under safe conditions.

But whereas the EU's Scientific Veterinary Committee is made up of independent experts appointed by the commission, the Standing Veterinary Committee is made up of the chief veterinary officers of their member states, who answer to their political masters.

The commission's proposal to lift the ban failed to obtain the qualified majority it needed to pass, after it was voted against by seven countries - Germany, Austria, Spain, Portugal ('the hard-liners') and Belgium, Luxembourg and the Netherlands. Their reasons for opposing the lifting of the ban were varied, but none can be described as scientific

Germany and Austria are under pressure from their powerful consumer and ecologist organizations to resist any concessions. Spain and Portugal voted against, not because they were concerned about the safety of beef derivatives as such but in protest at what they claim is insufficient progress in the culling of British cattle. Dutch vets argued that allow- ing British semen into the country would affect exports of Dutch semen.

The European Commission has since indicated that it will try to bypass the standing veterinary committee's decision and force through a lifting of the ban. In an unprecedented statement, the commission

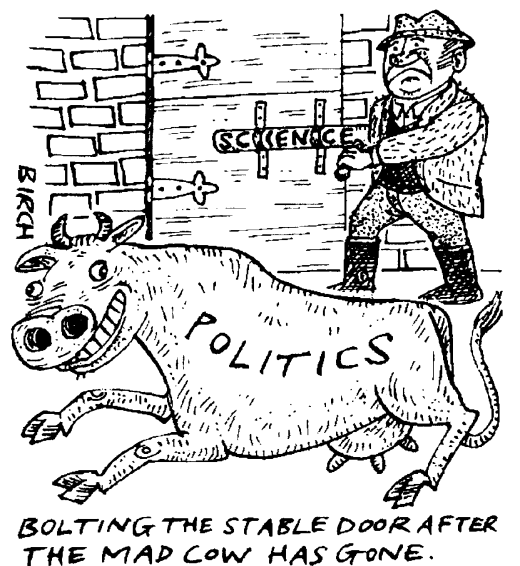

also said that "the veterinary committee had not respected the scientific data, and had married science and politics too readily".

Meanwhile, Britain has made much of the unscientific basis for last week's decision, in particular to justify its decision to block other EU business until the ban on derivatives is lifted, and progress is made towards lifting of the wider ban on British beef. But its complaints have received little sympathy in other parts of Europe.

It is pointed out that the British government has only itself to blame for the ban, given that it underestimated the impact of its announcement of a possible link between BSE and CJD, and failed to alert its European partners beforehand. Feeling are running particularly high because, while sales of beef have virtually recovered in Britain, the consumption in the rest of Europe remains badly affected by the crisis.

Indeed, unscientific or not, last week's decision is a gloomy omen of the prospects for scientific advice reasserting itself within the BSE debate, and for the wider ban on beef being lifted. Both the WHO and the OIE say that British beef is safe for consumption provided that certain precautions are taken in its production, even if the hypothesis of a link between BSE and CJD is correct. "Meat is as safe as it could be," says David Hayman director of WHO's

\section{Space agency warned on restructuring}

Munich. The European Space Agency (ESA) was warned last week that moves to separate planning of space missions from their implementation could jeopardize future space science programmes.

The warning came from David Southwood, professor of physics at Imperial College, London, and head of ESA's Science Programme Committee, in a letter to ESA director-general, Jean-Marie Luton. It follows Luton's presentation of plans for reorganizing ESA to members of the agency's council in Berlin.

Southwood says that he welcomes attempts to improve the operating efficiency of ESA, as required by Europe's space ministers at a meeting in Toulouse last October. He also accepts that separating planning and implementation could increase the efficiency of ESA's 'optional' programmes, such as Earth observation and the international space station.

But Southwood fears that such a move would not benefit the mandatory science programme. This is the only programme to which member states are obliged to contribute, and the resulting long-term predictability of budgets makes reliable planning possible. Until now, such planning, embodied in the Horizons 2000 programmes, has been carried out by the science directorate, which also controls the programmes themselves. "The director of science [Roger Bonnet] has a complete overview of the programmes, from cradle to grave, and that gives [them] great flexibility and efficiency", says Southwood. Chopping up the directorate horizontally "would throw away the one great advantage of the mandatory programme," he says.

The proposed new management structure for ESA will be discussed by its full council at the end of June. This timing has stirred fears that the reorganization may be carried out with undue haste during the summer.

Ken Pounds, chief executive of the UK Particle Physics and Astronomy Research Council, says that while it would be a "tragedy" if ESA lost the opportunity to streamline its administration, it would be "ridiculous to push through the suggested structure before hearing the considered advice of the scientific community".

Alison Abbott 


\section{Jefferson accelerator will seek to pin down quark theory}

Newport News, Virginia. The world's most powerful electron microscope was inaugurated by Hazel O'Leary, the US energy secretary, last week, enabling physicists to probe the structure of the nucleus and improve their understanding of the nature and function of quarks.

Completion of the $\$ 600$ million Continuous Electron Beam Accelerator Facility (CEBAF) on a green-field site in the Naval shipyard town of Newport News marks a considerable triumph for Hermann Grunder, the project director, who took control of the project in 1985 . Grunder radically altered its design to incorporate superconducting technology, while at the same time maintaining the political support needed to keep the project on track.

In a robust dedication speech last Friday (24 May), Grunder told his audience of 2,000 staff and invited guests that "times were too easy" when CEBAF got started. "Let me assure you that they're going to get tougher," he said. "We must do a better job of thanking our friends and obstructing our enemies."

CEBAF, which is managed by a specially created consortium of 41 universities in the southern United States, is already a success in one important sense. The South traditionally fares badly in terms of attracting federal science funds and their associated industrial spin-off. But CEBAF

\section{-emerging diseases division.}

But it still remains difficult to answer critics who argue that the best available scientific advice may not adequately predict future situations, concedes Howard Rees, chairman of the OIE's Code of Commission, and a former UK chief veterinary officer. "We can't say what will happen in ten years time," he admits. "We can only base our decisions on current knowledge; if something new comes along then we have to reconsider."

Germany feels, for example, that the UK government's belated acknowledgement of a possible link between BSE and CJD vindicates its demands since the beginning of the BSE epidemic in the 1980s for stricter precautionary measures to be taken. It is now acknowledged, for example, that the UK's 1989 ban on the use of cattle and sheep offal in feed for these animals was inadequate, in that it stopped short of prohibiting the feeding of offal to any farm animal.

Despite the ban, around 28,000 UK cattle have since become infected, mainly because they ate feed that had been contaminated with pig and poultry feed containing cattle and sheep offal. Only in March this year did the United Kingdom introduce a comprehensive ban on the use of offal in feed for all farm animals. A meeting of the OIE expert group on BSE concluded earlier this month that the new ban has already led to the creation of 127 new faculty positions at the 41 participating universities, more than doubling their strength in nuclear physics.

Experiments have been carried out at the facility since last November, when it began firing its continuous beam of electrons at an energy of $4 \mathrm{GeV}$ into stationary targets in one of its three underground target halls. Nearly 550 scientists from more than a hundred institutions will use the beam over the next year, probing nuclei to improve their understanding of how quarks build up the nucleus.

Their experiments will help to verify and refine the theory of quantum chromodynamics $(Q C D)$, which defines the 'strong force' holding nuclei together, in a manner analogous to that in which atomic physicists in the 1930s used experimentation to refine quantum electrodynamics (QED).

“Until now, we haven't had a sound scientific basis for understanding the nucleus," says Nathan Isgur, head of theory at CEBAF. Experiments at CEBAF will concentrate at first on the study of the simplest nuclei - deuterium, tritium, helium-3 and helium-4 - as the interactions of protons and neutrons in larger nuclei become alarmingly complicated.

Other electron accelerators, such as that at the Stanford Linear Accelerator Center in California, have delivered short

means that now "there should be no risk of infection from feed". Critics ask why such action was not taken sooner.

Suspicion of scientific advice is also being fuelled by the apparent emphasis of British politicians and government scientists in the past on trying to prove the negative case: that BSE could not pass to humans and cause CJD. As a result, much of the public now distrusts messages from scientists, who are seen - despite the caveats of some - to have been excessively reassuring.

Indeed, current research into the possible transmission of BSE to humans remains poorly geared to producing answers relevant to public health, according to Annick Alperovitch, head of the French CJD surveillance network and a member of the French and WHO expert committees on BSE/CJD.

Assurances about the safety of eating beef rely too much on experimental data, she says, whereas levels of infection that were so low as to be undetectable in such experiments could still create an epidemic, given the very large numbers of people who may have been exposed.

Similarly, while the $\mathrm{WHO}$ and other organizations point out that muscle tissue (beef) has never been shown to be infective, Alperovitch argues that this does not guarantee that infection might not occur under abattoir conditions, for example, through pulses of electrons, enabling physicists to study a few events at a time. In contrast, the continuous beam at CEBAF will permit the statistical study of hundreds of thousands of collisions every second. A veritable mountain of data will result: in Isgur's analogy, the 300 terabytes produced each year is equivalent to a detailed biography for every human being on Earth.

Roy Holt of the University of Illinois carried out one of the first experiments at CEBAF last November, using the beam to create $\gamma$ rays with which to split the simplest nucleus - the proton and neutron pair that make up deuterium. Don Geesaman of the Argonne National Laboratory in Illinois set up another experiment, studying the probability that a proton dislodged from a large nucleus will actually pass through it and escape.

During its battle for funding, CEBAF was dubbed the "Warnertron" in honour of Senator John Warner (Republican, Virginia), one of the project's most vigorous patrons, who attended last week's inauguration. Hazel O'Leary, who comes from Newport News, may have been sorely tempted to name it after herself. But she named it the Thomas Jefferson National Accelerator Facility, in memory of the only US president ever to declare that "politics is my duty, but science is my passion".

Colin Macilwain

contamination of beef by other tissues. The difficulty in extrapolating experimental data to the real world explains some of the divergent opinions among experts, she says.

It is important to recognize that science cannot provide certainties within the timescale demanded by politicians and the beef industry, says Alperovitch. "It is important to wait", she says, until epidemiological and other animal experiments clarify the situation towards the end of the year. In the interim period, expert committees will need to steer a course between reasonable precaution and over-reaction.

Whatever the scientific uncertainty about the links between BSE and CJD, many remain convinced that a return to using scientific advice in decision-making provides the only way out of the beef crisis. "My plea is to use more science," says Rees. "It is the only way we can get some rational decisions on this; with politics you don't get rational decisions."

But Rees also agrees that the ban on British beef is unlikely to be lifted soon. Irrespective of what scientific assurances are given as to beef's safety, what many European governments will retain is the hard fact that BSE is still widely present in British herds. They are likely to argue that a reasonable time to lift the ban will be when the UK government has eliminated the disease completely.

Declan Butler 